\title{
Adaptive Responsivity: A Youth-Driven Model for Thriving in Foster Care
}

Corey Shdaimah ( $\nabla$ cshdaimah@ssw.umaryland.edu )

University of Maryland School of Social Work https://orcid.org/0000-0002-5142-2831

Lucy Zhao

University of Maryland School of Social Work

Research Article

Keywords:

Posted Date: February 7th, 2022

DOI: https://doi.org/10.21203/rs.3.rs-1313110/v1

License: (9) (i) This work is licensed under a Creative Commons Attribution 4.0 International License. Read Full License 


\section{Abstract}

With notable and growing exceptions, there is a dearth of research on mechanisms by which youth in foster care build resilience and achieve positive outcomes. We report on data from an interview study with young adults exiting or recently exited foster care in Maryland ( $\mathrm{N}=15$ ) designed to understand what facilitates their engagement with courts. Our findings indicate that despite challenges of "being in foster care", youth found ways to pursue their goals and make their voices heard through developing stable relationships with supportive adults (including judges, caseworkers, or lawyers) and demanding that child welfare professionals "speak to me not at me." Youth indicated that their needs, capabilities, and goals changed as they matured and as their circumstances changed. Such changes helped them find their voices but also created tensions within their child-welfare system interactions. This led us to develop the theory of adaptive responsivity, according to which child welfare stakeholders should respond appropriately to developmental and circumstantial changes to help child-welfare involved youth face difficult circumstances and thrive. Such responses include providing developmentally and situationally appropriate information and decision-making power to youth in their own cases as well as opportunities to weigh in on systems change.

\section{Introduction}

Youth in foster care experience multiple challenges as they age and eventually transition out of the foster care system (Gypen et al., 2017). Most literature on child welfare trajectories are deficit-focused, meaning that they primarily engage with the very real negative experiences and outcomes of youth who grow up and exit from child protective services as young adults. With some notable and growing exceptions, there is a dearth of research on mechanisms by which youth in foster care build resiliency and achieve positive outcomes in the context of adverse circumstances (Kothari et al., 2020). Youth perspectives on how they perceive and successfully face challenges are also understudied (Smith et al., 2022)

In this article, we report on findings from a qualitative study comprised of semi-structured interviews with young adults (age 18 or older) exiting or recently exited ( $\mathrm{N}=15)$ from foster care across the state of Maryland. This study was designed to explore factors that facilitated and impeded youth engagement with dependency courts, whose role is often overlooked in the child welfare literature, and how this impacted youth's trajectories in care. Respondents described court engagement as intertwined with their experience in care more generally, and we elicited information on the roles of all professional child welfare stakeholders. Although we asked for both facilitators and impediments, respondents largely shared stories of resilience, positive outcomes, and overcoming adversity. We used an open-ended deductive analysis of findings that led us to develop a theory of what we call "adaptive responsivity," according to which child welfare stakeholders' ability and willingness to adapt to children's evolving developmental stages, social context, and aspirations have impact on youths' experiences of child welfare. Our qualitative, exploratory study suggests that child welfare stakeholders who are responsive to and support children emotionally, materially, and as advocates in ways that evolve as youth grow and change can contribute to positive outcomes in self-efficacy, self-esteem, and achievement of youth-identified goals.

\section{Literature Review}

While there is substantial literature focused on the challenges and negative outcomes experienced by youth in foster care, less attention has been paid to positive outcomes of youth and protective factors that contribute to such outcomes (Kothari et al., 2020). Of the literature that exists, a strong emphasis is placed on individual and interpersonal factors that promote youth resiliency, highlighting the need for stable and strong social support networks that promote youth's intrinsic strengths (Kothari et al., 2020; Zinn et al., 2017a; Zinn et al., 2017b). One scoping review of individual and interpersonal factors that influence psychosocial functioning of youth in foster care examined 41 peer-reviewed, quantitative studies (Kothari et al., 2020). Researchers found clear themes of modifiable individual factors that include personal strengths, psychosocial needs, and developmental skills, all of which influenced and were influenced by interpersonal factors (Kothari et al., 2020). Researchers examined three major relationship categories: peers and siblings, caregivers, and caring adults within the community (Kothari et al., 2020). Yet, the influence of foster courts and child welfare stakeholders was absent despite the evident role these entities play throughout youth's involvement in the foster care system (Kothari et al., 2020; Blakeslee \& Best, 2019). 
Indeed, one study exploring youth-identified support network factors via interviews with 22 youth in foster care found that caseworkers were a source of relational instability, which adversely impacted youth engagement and perceived support (Blakeslee \& Best, 2019). Study participants also noted how courts could disrupt other stable and supportive relationships, especially with family members, via court-imposed restrictions and/or foster care living situations (Blakeslee \& Best, 2019). However, the same study found that foster court-related service providers could also be a source of strong and stable relationships, with several respondents referring to their court service provider as "a trusted authority figure or like a parent" (Blakeslee \& Best, 2019, p. 225). Such positive relationships with service providers were correlated with perceived genuine support, long-term consistency, and opportunities for youth in active decision-making (Blakeslee \& Best, 2019). Moreover, strong relationships with service providers facilitated the formation of new connections, relationships, and increased service engagement, all of which contributed to positive outcomes and experiences of youth in foster care (Blakeslee \& Best, 2019).

Other efforts to understand protective support factors underscore the evolving nature of social support networks as youth mature in foster care and transition into adulthood (Zinn et al., 2017a; Hokanson et al., 2019). Drawing on data from a longitudinal panel survey of youth in foster care, Zinn and colleagues (2017a) found that lower levels of support created greater instability in social support trajectories, with differences further exacerbated when transitioning into adulthood. Lower baseline measures of support also reflected less adequate social networks and may be associated with poorer social-emotional skills of affected youth, resulting in greater difficulties and greater social support loss when transitioning out of the foster care system (Zinn et al., 2017a). Similarly, as youth in foster care become emerging adults, tensions arise between youth's desire for independence and their continuing need for developmentally appropriate interdependence (Hokanson et al., 2019). Indeed, the regulatory nature of the foster care system was perceived as a major limitation to youth's ability to exercise and grow their self-efficacy skills despite the pressure from courts to be self-sufficient (Hokanson et al., 2019).

Although extensive research has been devoted to understanding youth's experiences and challenges in the foster care system, gaps in knowledge remain. Specifically, youth perceptions regarding the role of courts and its actors, such as judges, caseworkers, court appointed special advocates (CASAs), and other service providers, in youth development and success have yet to be thoroughly explored. A paucity of studies centers on the role of courts and child welfare stakeholders in mediating and facilitating youths' strengths and resilience. This study attempts to contribute to the literature by exploring the influence of foster courts and related actors in how youth engage with the foster care system, how this engagement evolves and changes as youth age through the system, and positive facilitating factors that youth themselves perceive to be critical to their success.

\section{Methods}

The current study elicited feedback from young adults age 18 or over currently or formerly in foster care in Maryland to learn what they perceive as factors that impede and facilitate meaningful and effective engagement and support in meeting selfidentified goals while in foster care, often from when they were young children. We also sought recommendations for how court engagement may improve experiences and outcomes for youth involved in care. While our questions focused on the courts, respondents told us that engaging with a variety of child welfare stakeholders was important, and that their ability to survive and thrive within and beyond foster care and into adulthood depended on their own efforts combined with support from these systems and/or particular professional stakeholders. Our detailed findings follow the methods below.

\section{Study Design and Sample}

To elicit youth perspectives on experiences in foster care, this study employed features of grounded theory methodology (Charmaz, 2014). More specifically, we used a phenomenological approach to learn how respondents understood their own experiences; a constant comparative approach to data collection and analysis; and sought description and theorygeneration as products for our analysis. The study was designed and carried out by the authors who served as the PI and research assistant, respectively, in consultation with the Maryland Foster Care Court Improvement Program [FCCIP]. The study received [University] Institutional Review Board approval.

The FCCIP disseminated a recruitment flyer via email to attorneys representing children and youth in foster care, Maryland's Department of Human Services Foster Care Ombudsman, and all local Departments of Human Services. The flyer invited 
interested young adults aged 18 and over who were engaged with foster care or had exited care within the past five years to contact the PI. Participation consisted of a one-time semi-structure interview, conducted virtually as dictated by state and [University] COVID-19 guidelines. While our questions focused on engagement with the courts, we asked what services or supports respondents would like to see more generally and what advice they would give to other youth in care. We also invited respondents to share any other information that they deemed relevant to their experiences in foster care or with the courts. The study was confidential; all names that we use in this article are pseudonyms chosen by respondents. Interviews conducted by the authors lasted approximately 30-70 minutes and were digitally recorded and transcribed verbatim. All respondents received a $\$ 20$ electronic gift card as compensation for their time.

Respondent ages ranged from 18-25. For sample demographics on gender, racial/ethnic identity, and time in foster care see Table 1. Respondents were from rural, suburban, and urban areas statewide from ten of Maryland's 23 counties:

[TABLE 1 HERE]

\section{Data analysis}

We analyzed the data to generate descriptive analysis of respondents' perceptions (Sandelowski, 2000). We sought to identify what factors impeded and facilitated meaningful court engagement and other facets of their child welfare trajectories. We used Maguire and Delahunt's (2017) five-step thematic analysis process.

Initially, we immersed ourselves in the transcripts while listening to the corresponding audio-recordings or video-recordings, taking audio or written notes about our emergent understanding. Next, we coded one sample transcript, selected for its richness, to generate initial codes. Codes were created using participants' own words (in vivo codes), such as "tick tock" and "when you're in foster care," when possible. We then met to review and create a consensus coding scheme. In Step 3, we applied our consensus coding scheme to all interviews and looked for patterns, discontinuities, and overarching themes within the data. In step 4, we reviewed the codes and sorted them by theme to develop a larger picture. In the final step, we refined and re-sorted the codes and themes through the process of writing.

To enhance the trustworthiness of the research, we engaged in weekly or bi-weekly debriefing during data collection and data analysis, actively searched for disconfirming evidence to test our emerging interpretation, and retained an audit trail (Padgett, 2016). Use of the constant comparative method of conducting data analysis while engaged in data collection also allowed us to conduct in member-checking, testing our emerging understanding of the data as we continued to collect data in later interviews (Glaser \& Strauss, 1967).

\section{Findings}

The overarching message from youth in our sample was that the professional child welfare stakeholders and institutions play a crucial mediating role in respondents' experiences with foster care. Their potential impact was dynamic, varying with age and developmental stage of the youth. The role that the courts, specifically, played in the lives of respondents also seemed to be both cause and effect of implicit and explicit messages that youth received from the court and other stakeholders. In other words, perceived openness and support from the bench had a reciprocal and mutually reinforcing relationship with youth engagement. In the following subsections, we expound on each theme.

\section{"When you're in foster care...": The Ongoing Context for Youth in Foster Care}

Respondents shared the many emotional, bureaucratic, social, and educational challenges that they had faced. Many entered foster care with trauma and little support. These challenges were sometimes compounded by court interactions and feelings of lack of control or transparency. Several respondents reported that child welfare professionals assumed that youth are incapable of making decisions or saw them as troublemakers. Distrust and troubled communication were exacerbated by challenges that flowed from their age and developmental stage, as well as troubled relationships with court stakeholders, families of origin, and foster families. Kay's "traumatizing" encounter in the courts was when she was called to be a witness regarding "accusations that my mom was abusing me, which she was." Kay described herself as "an angry child who was kind of pawned all over the 
place." This experience left a lasting impact, "they pretty much just ate me alive on the stand and you can't really prepare a 13 year old for that, especially an angry non-understanding 13 year old." Kay's explanation is instructive of how children who are victims of abuse and neglect by adults in their lives may come into systems that fail to respond with understanding.

....as a kid, when basically your whole entire life, all you know, is crashing, it creates behavioral issues. So there was a lot of lashing out. So they painted this picture to the court that I was this juvenile delinquent essentially and I was just destructive and self-destructive and explosive, which granted, I was. So I didn't feel like I had anybody in my corner at 13.

Kay's helplessness and fear were magnified by her sense that nobody was interested in her perspective or wellbeing. She sees a major barrier to youth engagement as "trying to get grown adults with authority to listen to kids with behavioral issues."

Four respondents indicated that race or ethnicity played a role in their foster care or court experience. Sierra said that having a Black caseworker was central to her ability to process her own experiences as a Black woman. Virginia always worried how she would fare in court and in care: "I'm Black so it's just like a pre-existing fear I would say. Kind of like you automatically, almost like you automatically think...oh my god, whatever could happen I know I might just get the worst instead of the best." Kay believed that she was treated better because she was a white woman; when she advocated for herself in court, the judge called her "feisty" and "said she could see me being in her place." Kay reflected "If I was a Black male, I probably would have not been received as well as I was." On the other hand, Ivania noted that child welfare service's prioritization of matching her with a Hispanic foster family to maintain her linguistic heritage hampered rather than helped her, due to a mismatch around the family's ability to support educational aspirations that she prioritized. While most respondents did not bring up race and ethnicity or believed it was a factor when we asked directly, these four saw it as an important influence on the way they were treated as youth in care.

Respondents also described instability due to frequent moves and the isolation and "otherness" that they experienced as children for whom "regular" childhood activities such as sleepovers with friends and driving lessons are complicated by heightened oversight and bureaucratic processes. Despite additional challenges, most respondents overcame miscommunication and limited voice, finding or creating opportunities to speak up and shape their own trajectory through foster care and into emerging adulthood.

\section{Change and Continuity}

Frequent changes feature strongly in respondents' experience of foster care. They attributed the majority of disruptions that they experienced to inconsistencies in people involved in their cases (e.g. magistrates, caseworkers, and lawyers) and frequent moves between various foster and group homes. Because respondents already faced challenges that precipitated and stemmed from their involvement in foster care, such changes compounded their difficulties and stress. Genesis found it "problematic" to continually adjust to "changing caseworkers like I was changing underwear," requiring her to re-orient each new stakeholder:

I would always ask my caseworker, "Are you staying for a while? Because I don't want to open up about something and then you're not here tomorrow." And then it's like now I got to explain the same situation to another worker.

Her wariness (and weariness) of sharing impeded Genesis's ability to interact and engage. Changes also tarnish youths' perceptions of court productivity: "if you get a judge that's not familiar with your case, most of it's just hearsay from the files, and...the odds of it being successful are way up in the air."

Respondents indicated that judicial continuity allowed for the court to serve as a coordinating hub, and where other child welfare stakeholders could both be held accountable and brainstorm about their specific cases. Jade strategically raised concerns in open court:

I wanted to bring it up in court to see, because then it was like they would need to have an answer...: I'm hearing it from such and such and I want to know if they actually do this, that you have those resources, what's out there for me?" 
Consistent adult stakeholders helped respondents develop better relationships, communicate more openly, and promoted greater trust generally and in relation to the court. Having the same judge was especially important to Sierra in light of frequent turnover over other stakeholders, whose judge "was the only constant thing throughout my time in foster care. And everything else changed; social workers changed, lawyers changed. But my judge was the same the entire time. She actually did a good job at protecting."

Consistency also fostered familiarity; Sierra said that when she was anxious or uncomfortable, her judge "noticed that and tried her best to be supportive." Likewise, consistent and meaningful relationships with lawyers and caseworkers supported respondents' self-advocacy and sense of protection. Jade said of her attorney:

She always encouraged me to speak up about things because I know that I was very timid my first time in the courts but after years of doing it, I just realized that being your own advocate is the best and also just being able to utilize what resources or help is there in the court like your lawyer, your social worker, your judge, all of them are there to support you and help you.

Jade's close relationship helped her attorney be a better advocate: “I often ask my questions one-on-one and my attorney definitely spoke on my behalf to the judge."

Together with the advantages of consistency noted above, some respondents acknowledged the benefits of changes, especially when previous or current stakeholders were ineffective, unresponsive, or a poor fit. Amber found it "nice having new judges and magistrates pop in every once in a while because they could have a new perspective on the case." For others, changes in judges, magistrates, and other court members had little impact on their engagement. When asked to compare between her two judges, Barbie felt that "they were all the same...no difference." Echoing similar sentiments, Jeffrey, who also had two different judges, noted how "they all got the same job practically so I wouldn't mind [the changes]."

Overall, it appears that frequent changes often had a negative impact on respondents' foster care trajectories, while occasional or limited changes may give rise to new opportunities or relationships. Consistency in judicial decision-makers seemed especially important for youth who lacked consistency with other stakeholders or in other parts of their lives. Likewise, consistent caseworkers and lawyers were a source of meaningful relationships with a caring adult who supported respondents' abilities to self-advocate and intervened on their behalf.

\section{Communication}

Respondents noted the importance of attending to children's developmental stages and their unique personalities and interactional styles. James was initially shy and felt alienated by the courts, caseworkers, and an abusive foster home. The combination of moving to a safer living situation and finding a supportive caseworker changed things for him. His new caseworker "reached out" and told him "hey, you can speak your mind and everything, we want to know what's going on with you and how to make you more comfortable and how to improve things." This also coincided with James' maturity, "when I was older and I could finally speak for myself, and I was more independent and stuff. Things were just a lot better. It was just a lot easier." James felt most heard in court:

I always felt that I was [maybe] 'number one priority'... [and] like I was important, like I could be heard...Especially when the magistrate also liked me and is very, very friendly. [When] I was a kid...it was a little scary. But as I've gotten older it just got more and more comfortable. And my support system would grow and grow and grow.

Respondents underscored their positive experiences with age-appropriate communication and transparency about the foster care system. Conversely, lack of communication impeded respondents' ability to engage with the courts, for example, when they were not informed about hearings or when they were not provided an opportunity to speak up.

Respondents emphasized the need for all child welfare stakeholders to adapt communication so as to invite input, especially when children and youth feel shy or intimidated. Tiffany often felt too intimated to speak openly in court, even when given the opportunity: 
I was always nervous to talk to a judge. 'Cause I'm like you are this so high and mighty powerful person. If I say any wrong thing to you and it's, man, my ass is grass. So I just get so nervous I didn't know what to say, l'd just agree like 'yes sir, yes ma'am. I don't know l'm just going to agree with you.'

Ivania also underscored the need to provide opportunities for private communication. She was uncomfortable being the subject of discussion in open court as a 10-year old who "[didn't] like having attention on me." She described an incident when her foster mother spoke to her inappropriately, explaining that courts "need to pry it out of children, I think, because for me...I wish someone had pried it out... because some [children in care] may not know, 'oh, this isn't appropriate for my foster parents to be saying.....little kids are so vulnerable."

Sierra credited her social worker's advice as one of her guiding principles "if you want something, ask for it. Closed mouths don't get fed." Sierra emphasized the importance of youth in care to develop self-advocacy skills:

I just had so many opportunities that I felt like I missed out on because I was depressed or stuck on not communicating. And you look back on those times and you're like, 'wow, it could have been solved with a simple phone call or something.' But I didn't want to do that because [I] was being scared or something. And that's okay, but in the system, like I said, closed mouths don't get fed, you only fail by not trying.

Most respondents stressed the need to self-advocate, often pointing out a trusted adult who helped facilitated such advocacy in ways that were appropriate to their changing needs.

\section{Respondents' Changing Needs}

As respondents matured and progressed through foster care, they experienced developmental changes and critical life events. Many difficulties stemmed from challenges to authority as they moved toward adulthood within the restrictions of foster care and dependency court oversight. Respondents weighed the value of remaining in care against the knowledge that it came with heightened intrusion and restrictions.

Most respondents believed that the benefits of foster care outweighed its burdens, especially in the absence of other resources. Barbie advised other youth to "sta[y] in care because I aged out at 18 so just stay in care and try to make it at least to 21 because you receive more help afterwards." As Delonte neared adulthood, he "realized DSS [Department of Social Services] is not a joke. If you don't take them seriously, they will definitely close your case and let you be hard up." He was nervous about leaving his supportive network, in which his judge played a key role:

[T]he judge used to always ask me if there was anything I wanted, do I want to go to college, or what do I want to do, or do I want to go to trade school. And if I said 'yeah,' the judge ordered it or ordered the assessment like, 'ok, we'll refer him to some programs' or point him in the right direction. The judges and the court, as far as I know, always led me in the right direction. Always asked me what's my finishing goals and that 21 for me was right around the corner.

Likewise, at Jeffrey's last hearing: "time was ticking. I was getting older." He shared his sense of accomplishment, noting the role of the court: "They raised a good young man."

Amber was among the three respondents who exited care at 18 (one of the three, Kay, reentered to leave again at 21). Amber's decision was driven by her resentment of the demands of foster care on her time and its intrusiveness, especially since she did not perceive the services she received as helpful in preparing her for adulthood:

[A]t 18, obviously you're entering adulthood and it's like they're still treating you like you're this small child that entered into foster care. Now, with the housing vouchers, they don't allow this and they don't allow that... [T] he main goal after 18 is to push for independent living. [Staying in care] was not pushing for independent living because you're still doing the same thing that you were doing in foster care, all while having more responsibility, dealing with meetings and then looking over your bank account and this and that. I feel like that's just an invasion of privacy. 
Such sentiments were particularly salient for respondents with children, who mentioned conflict around their freedom to make parental decisions. Laura was torn between her fear of facing adulthood alone and intrusive scrutiny, especially related to her parenting, who worried "about leaving care because I knew for a fact that I wouldn't have someone" but at the same time didn't want to be "under a microscope, having someone watch my every move trying to tell me what to do with my child, my children, none of that."

The majority of respondents became more active in hearings when they were older adolescents, often due to a combination of stakeholder perceptions of their maturity and their growing sense of agency and a desire for knowledge and control. According to Laura, who was in foster care as a younger child and reentered at 16 ,

The first times someone explained something to me was when I turned 16 and got back in the system. Because at that point, I was more vocal and I knew what I wanted and I was more knowledgeable about the things that they could do. So I wanted to know what all these big legal terms meant and what they were talking about. So I spoke up and I asked but I don't think a foster child should have to speak up and ask, you should just explain it to them.

Laura persisted despite the fact that not all stakeholders welcomed her self-advocacy, "when I asked questions, they would be a little like snippy with me. Like they had an issue with me asking questions and I'm like 'I don't care because I need to know what's going on."'

In sum, youth who were able to self-advocate experienced significant improvement in their court experiences, which in turn often helped them access resources and gain greater knowledge and control over facets of their life. Those whose self-advocacy did not produce desired results disengaged with the courts and with foster care in general. While self-advocacy may stem from typical development changes, respondents primarily associated it with a growing understanding of the court system and the receptivity and encouragement of the court and other child welfare stakeholders to their active participation.

\section{Discussion And Recommendations}

Our findings below point to a number of implications and recommendations for the courts and other child welfare stakeholders. In addition to the detailed recommendations, our findings suggest an overarching need for flexibility and consideration of children's age, development stage, and current situation. They also underscore the importance of eliciting perspectives from those formerly and currently in foster care in order.

\section{Role of the Bench}

Our findings confirm prior research that emphasizes the importance of network stability in the lives of youth in foster care (Blakeslee \& Best, 2019; Kothari et al., 2020). It also adds to this literature by explicating how judges can foster stability for youth, including by themselves serving as one of the stable adult professional stakeholders within the networks of youth in foster care. This seemed particularly important when other stakeholders, such as caseworkers or lawyers, changed and when youth experienced multiple changes, in which case a judge who knew them, and whom they knew, was an important source of stability. To this end, our findings also corroborate the benefits of the one-judge, one-family model (National Council of Juvenile and Family Court Judges, 2012; Authors, 2013). Most respondents appreciated having one consistent judge who at times also functioned as the one consistent, trusted adult in their life over time. Judicial consistency may also help to ensure that decisions are made within a context of familiarity with the respondent's particular story, intersectional identities, and changing needs. This may include traumatic experiences, placement instability, and changing family relationships. Such knowledge can guide courts in their oversight role to ensure that all child welfare stakeholders understand and respond appropriately in their interactions with children and youth.

The court also emerged as an important touchstone for respondents as they formulated and worked toward future goals. All child welfare stakeholders can use hearings as a shared opportunity to elicit and encourage youth to envision future career and life aspirations early. The court can encourage and help identify meaningful resources and support, serving as both a forum for future-oriented discussion with children in care and a coordinating hub where they can learn about and get connected to available resources, such as tutoring, driving lessons, internships, or post-secondary education. Finally, the courts can provide 
opportunities for children and young adults in care to re-evaluate and re-assess their progress and hold other relevant stakeholders accountable. For example [County] Court employs a judicial bench-card that all child welfare stakeholders use to discuss and track the progress of youth in care as they approach emancipation (Authors, 2021).

\section{Adaptive Responsivity: A Dynamic Youth-Centered Approach}

Our findings underscore the need for an approach that is both youth-centered and adaptable to children's changing needs, which we call "adaptive responsivity," in all aspects of child welfare, including dependency court. Adaptive responsivity recognizes the evolving desire of youth to have greater knowledge and control over decisions that impact their lives, which is consistent with prior research. Respondents' desire for greater say in court proceedings and in their child welfare trajectories was also predicated on an expectation that all stakeholders communicate directly and openly. This includes sharing technical and logistical information, such as when the next court hearing is, who will be present, and its purpose. However, it is also clear that such information and how it is communicated must be appropriate and responsive to youth's needs and capabilities which can and grow as their circumstances and development change.

Our findings indicate that when stakeholders withhold information, even if they deem it in the best interest of a child, the resulting uncertainty creates fears that must be recognized and addressed. Children in foster care should therefore be provided with as much information as possible, conveyed in a developmentally appropriate manner. During difficult conversations the presence of appropriate support persons, such as a trusted and familiar adult or someone with requisite professional expertise, should be considered. This is especially important when professional stakeholders such as judges or lawyers may not have training to handle difficult conversations and when settings (such as courts) may be intimidating.

Training for child welfare stakeholders on social, emotional, and cognitive development would also be valuable. In keeping with adaptive responsivity, such knowledge would help child welfare stakeholders better understand and meet the needs of youth in care to appropriately match youths' evolving maturity and circumstances. Such training is particularly important for courts and other child welfare stakeholders working with youth in foster care experiencing emotional or mental health crises, which impeded some of our respondents' ability to communicate and led them to behave in ways that thwarted their goals and aspirations. Better stakeholder understanding may lead to greater empathy and more suitable interventions to help youth and prevent exacerbation of their challenges or compounding their sense of isolation and lack of control (Office of the Administration for Children and Youth, 2020; Villagrana, 2021). There is also the need for systems that are better designed to enable all professional stakeholders to respond to children and youth who may be affected by their challenging experiences with empathy. Courts and other child welfare stakeholders need appropriate education, sustainable caseloads, and community resources, all of which require greater investments to best serve children in foster care and their families. For example, researchers and policymakers continue to call for trauma-informed child welfare approaches (Casey Family Programs, 2018; Ko et al., 2008).

In addition to mental health knowledge, it is important that child welfare stakeholders be cognizant of child development, and how child welfare systems may create hurdles or higher stakes for youth who mature within care. Similar to Hokanson et al. (2019), we found that the dual desire for independence and support are often misunderstood as problematic tensions rather than age-appropriate recalibration of interdependence. Existing literature indicates that pregnant and parenting youth in foster care may have unique challenges (Rouse et al., 2021). Our findings also indicate that parenting can create a new orientation toward engagement with the courts and child welfare systems, and a failure to recognize the need for greater power in decision-making may undermine youth's responsibility as parents. Efforts should be made to allow for greater autonomy as youth mature and reconsider the value of beneficial supports against the burden of continued restrictions and supervision that accompany foster care system involvement and court oversight.

Better understanding of differential experiences of children and youth due to gender, ethnicity, and race is a critical component of adaptive responsivity. One quarter of respondents described their experiences through the lens of their ethnic or racial identity. Several women respondents described how gender and sexuality shaped their experience and research shows that sexual orientation and gender identity may also influence children's experience of the foster system (Wilson \& Kastanis, 2015). The courts and other child welfare stakeholders need to acknowledge and be responsive the experiences of different youth along axes of identity; they must also engage with youth in how best to prioritize their concerns and support them. For example, some

Page 9/12 
of our respondents found racial concordance helpful, whereas another respondent was frustrated that her child welfare workers prioritized language and cultural concordance over educational goals without consulting her.

The lens of adaptive responsivity should also be applied to agencies and policies, which are also part of youth's differential experiences. It is well documented that historical and ongoing forms of harm within and outside of child welfare systems such as racism, poverty, and other systems of oppression are part of the harm experienced by a majority of families engaged with foster care systems (Dettlaff \& Boyd, 2020). While individual child welfare stakeholders may not be able to immediately dismantle these, they should acknowledge and respond to the diverse challenges that youth and their families may face within structurally racist and oppressive systems, including child welfare and broader society. They should also engage in meso actions within their agencies and calls for macro changes at the societal level to the best of their ability. This is especially true for social workers, whose Code of Ethics calls for such multi-level engagement (National Association of Social Workers, 2021).

\section{Mechanisms for Sharing Feedback}

In addition to the specific recommendations outlined here, our study provides support for efforts to engage youth in providing feedback to the courts and other child welfare stakeholders in matters that impact them and other children in care. There is a clear need for enhancing the ability of children and youth to communicate safety concerns, particularly when they are vulnerable. While several respondents ultimately succeeded in changing harmful or inappropriate placements or workers, their troubling accounts highlight the difficulties of communicating and accessing help for themselves or siblings in a timely manner. Creating more pathways for providing feedback in individual cases, such as the [State] Ombuds or the Youth Advisory Board [citations omitted for review] may help when individuals wish to report concerns but are afraid to do so because of their vulnerability. Such mechanisms provide youth with the opportunities for control and influence over their own case and also to help and connect to others locally and nationally through peer-led organizations such as the National Foster Youth Institute (2022),

Those with personal experience of foster care may be best positioned to inform child welfare stakeholders about their own experiences and provide insights in what may help children and youth who are moving through care under supervision of the courts. This would mean augmenting youths' say in their own lives by providing them with opportunities to impact the systems that serve them and other youth in care. To this end, youth should also be involved in helping to assess and monitor any changes or improvements.

\section{Limitations}

The majority of respondents had an overall positive view of their experiences of the courts and the foster care system, which may reflect a sampling bias toward youth who were connected to important child welfare stakeholders. Respondents may therefore have had very different experiences than youth who had more negative interactions with the courts and/or with child welfare stakeholders. This limitation may be partially mitigated by respondents' descriptions of both positive and negative experiences over the course of their time in foster care, as well as their description of siblings' experiences that differed from their own. Even if the sample has a positive bias, it enables us to learn what best practices for self-identified successful engagement.

Another limitation is the small sample size and the fact that all respondents were from one state. We attempted to mitigate this limitation by drawing from different counties with a diversity of jurisdictional, demographic, and populations density. The sample size is appropriate for an exploratory study and the clear pattern that emerged across respondents across jurisdictions is promising, as is the corroboration with other studies. However, further research with a larger and more diverse sample and in other contexts is necessary to assess transferability of our findings, including those that corroborate existing studies, and to test our own emerging concept of adaptive responsivity (Maxwell, 2021). In particular, longitudinal mixed methods research to chart the intersection of developmental and contextual changes with foster care trajectories would help to track and explicate such changes over time.

\section{Conclusion}

Respondents in our study were overall satisfied with their court engagement and foster care trajectories and viewed judges as key actors in their experience of foster care. However, this satisfaction was often arrived at only with the intervention of a trusted and

Page $10 / 12$ 
stable adult which could be a judge, caseworker or lawyer, as well as with the youth's own growing maturity and sense of self. While this should be obvious, foster care is precipitated by difficult and often traumatizing family circumstances; involvement in the foster care system itself can also be isolating, stigmatizing, and disruptive. Respondents noted the many hurdles to arriving at positive outcomes, including fear, trauma, the court environment, instability, and lack of knowledge. Our findings show that courts and other child welfare stakeholders who act through a framework of adaptative responsibility to provide developmentally and situationally appropriate support, services, and encouragement can help youth thrive in and beyond foster care.

Given that our respondents were referred to the study through their existing connections to foster care stakeholders, we can assume that our small sample was biased toward youth with relatively positive experiences, meaning that the majority of youth in foster care have worse experiences. This likely means that our sample serves as a model for how courts and other stakeholders might provide support that others would benefit from but may not be receiving.

\section{References}

1. Authors (2013).

2. Authors (2021).

3. Blakeslee, J. E., \& Best, J. I. (2019). Understanding support network capacity during the transition from foster care: Youthidentified barriers, facilitators, and enhancement strategies. Children and Youth Services Review, 96, 220-230. https://doi.org/10.1016/j.childyouth.2018.11.049

4. Casey Family Programs (2018). Healthy organizations: Why should child protection agencies become trauma-informed. https://caseyfamilypro-wpengine.netdna-ssl.com/media/SComm_Trauma-informed-1.pdf

5. Charmaz, K. (2014). Constructing grounded theory (2nd ed.). Sage Publications

6. Dettlaff, A. J., \& Boyd, R. (2020). Racial disproportionality and disparities in the child welfare system: Why do they exist, and what can be done to address them? The ANNALS of the American Academy of Political and Social Science, 692(1), 253274. https://doi.org/10.1177/0002716220980329

7. Glaser, B. G., \& Strauss, A. L. (1967). The Discovery of Grounded Theory: Strategies for Qualitative Research. AldineTransactions, Transaction Publishers

8. Gypen, L., Vanderfaeillie, J., De Maeyer, S., Belenger, L., \& Van Holen, F. (2017). Outcomes of children who grew up in foster care: Systematic-review. Children and Youth Services Review, 76, 74-83. https://doi.org/10.1016/j.childyouth.2017.02.035

9. Hokanson, K., Golden, K. E., Singer, E., \& Berzin, S. C. (2019). 'Not independent enough': Exploring the tension between independence and interdependence among former youth in foster care who are emerging adults. Child Welfare, 97(5), 141157. Retrieved from

https://www.researchgate.net/publication/340037274_Exploring_the_Tension_Between_Independence_and_Interdependence _among_Former_Youth_in_Foster_Care_who_are_Emerging_Adults

10. Ko, S. J., Ford, J. D., Kassam-Adams, N., Berkowitz, S. J., Wilson, C., Wong, M., \& Layne, C. M. (2008). Creating traumainformed systems: Child welfare, education, first responders, health care, juvenile justice. Professional Psychology: Research and Practice, 39(4), 396-404. https://doi.apa.org/doiLanding?doi=10.1037\%2F0735-7028.39.4.396

11. Kothari, B. H., Blakeslee, J., \& Miller, R. (2020). Individual and interpersonal factors associated with psychosocial functioning among adolescents in foster care: A scoping review. Children and Youth Services Review, 118, 105454.

https://doi.org/10.1016/j.childyouth.2020.105454

12. Maguire, M., \& Delahunt, B. (2017). Doing a thematic analysis: A practical, step-by-step guide for learning and teaching scholars. AISHE-J: The All Ireland Journal of Teaching \& Learning in Higher Education, 9(3), 3351-33514. http://ojs.aishe.org/index.php/aishe-j/article/view/335

13. Maxwell, J. A. (2021). Why qualitative methods are necessary for generalization. Qualitative Psychology, 8(1), 111-118. https://doi.org/10.1037/qup0000173

14. National Association of Social Workers (2021). Code of ethics. https://www.socialworkers.org/About/Ethics/Code-ofEthics/Code-of-Ethics-English

Page $11 / 12$ 
15. National Council of Juvenile and Family Court Judges (2012). Project ONE key principles. https://www.ncjfcj.org/wpcontent/uploads/2012/09/Project_ONE_Key_Principles_July_2012.pdf

16. National Youth Foster Institute (2022). NFYI local chapters across America. https://nfyi.org/local/

17. Office of the Administration for Children and Youth, Children's Bureau (2020). The importance of a trauma-informed child welfare system. https://www.childwelfare.gov/pubPDFs/trauma_informed.pdf

18. Padgett, D. K. (2016). Qualitative methods in social work research (3rd ed.). Sage Publications

19. Rouse, H. L., Hurt, T. R., Melby, J. N., Bartel, M., McCurdy, B., McKnight, E. ... Weems, C. F. (2021). Pregnancy and parenting among youth transitioning from foster care: A mixed methods study. Child \& Youth Care Forum, 50, 167-197. https://doi.org/10.1007/s10566-020-09567-0

20. Sandelowski, M. (2000). Whatever happened to qualitative description? Research in Nursing and Health, 23(4), 334-340. https://doi.org/10.1002/1098-240X(200008)23:4\%3C334::AID-NUR9\%3E3.0.C0;2-G

21. Smith, A. C. G., Crooks, C. V., \& Baker, L. (2022). "You have to be resilient": A qualitative study exploring advice newcomer youth have for other newcomer youth. Child and Adolescent Social Work Journal. https://doi.org/10.1007/s10560-02100807-3

22. Villagrana, M. (2021). Foster care alumni's perceptions of mental health services received while in foster care.Child and Adolescent Social Work Journalhttps://doi.org/10.1007/s10560-021-00803-7

23. Wilson, B. D. M., \& Kastanis, A. A. (2015). Sexual and gender minority disproportionality and disparities in child welfare: A population-based study. Children and Youth Services Review, 58, 11-17. https://doi.org/10.1016/j.childyouth.2015.08.016

24. Zinn, A., Palmer, A. N., \& Nam, E. (2017). Developmental heterogeneity of perceived social support among former foster youth. Children and Youth Services Review, 76, 51-58. https://doi.org/10.1016/j.childyouth.2017.02.032

25. Zinn, A., Palmer, A. N., \& Nam, E. (2017). The predictors of perceived social support among former foster youth. Child Abuse \& Neglect, 72, 172-183. https://doi.org/10.1016/j.chiabu.2017.07.015

\section{Tables}

Table 1 Youth Characteristics $(N=15)$

\begin{tabular}{|ll|}
\hline Variable & $n$ \\
\hline Gender & \\
\hline Male & 2 \\
\hline Female & 13 \\
\hline Race & 3 \\
White & 11 \\
African American/Black & $3-16$ \\
\hline Number of Years in Foster Care & \\
\hline
\end{tabular}

